\title{
A FORMAÇÃO DE ATITUDES E O COMPORTAMENTO PÚBLICO DO BRASILEIRO EM RELAÇÃO AO 'LIXO’ QUE PRODUZ
}

\section{Jacqueline Cunha de Vasconcelos Martins}

Professora Substituta do Centro Federal de Educação Tecnológica do Rio Grande do Norte - CEFET-RN/UNED; Especialista em Filosofia - jcvasconcelos13@hotmail.com

Recebido em agosto/2004 e Aceito em dezembro/2004

\section{RESUMO}

Este artigo objetiva tecer considerações sobre a percepção e o comportamento do brasileiro no espaço público, especificamente em relação ao lixo - uma das grandes preocupações da sociedade moderna -, com impactos diretos no meio ambiente e na sociabilidade. Assim, parte-se de uma abordagem acerca das origens da atual sociedade de consumo, a verdadeira fonte da produção desenfreada de lixo, para, em seguida, analisar o comportamento do brasileiro, com enfoque mais específico para a formação de atitudes, onde a educação ambiental apresenta-se como uma possibilidade viável. Sem pretender esgotar os conteúdos relativos ao tema, este artigo trata de uma revisão bibliográfica preliminar.

Palavras-chave: consumismo; lixo; formação de atitudes; educação ambiental.

\section{THE FORMATION OF ATTITUDES AND PUBLIC BEHAVIOR OF THE BRAZILIAN IN RELATION TO THE GARBAGE THAT PRODUCES}

\begin{abstract}
This article aims at providing considerations about the perception and behavior of the brazilian citizen in the public space, specifically concerning the garbage - one of the greatest preoccupations of modern society -, with direct impacts in the environment and in sociability. So, this matter approaches the current consuming of society, the real source of uncontrolled production of garbage, then, we can analyze the behavior of Brazilian citizen, with specific focus on the formation of attitudes, where environmental education comes as a practical possibility. With no intent of ceasing the content concerning the theme, this article focuses on a preliminary bibliographic review.
\end{abstract}

Key words: consumerism; garbage; formation of attitudes; environmental education. 


\section{A FORMAÇÃO DE ATITUDES E O COMPORTAMENTO PÚBLICO DO BRASILEIRO EM RELAÇÃO AO 'LIXO’ QUE PRODUZ}

\section{INTRODUÇÃO}

A idéia de que a natureza existe unicamente com a finalidade de satisfazer as vontades humanas predominou durante séculos, sem que se questionasse os limites desse usufruto. Pautados por este princípio estão o modelo político-social dominante da sociedade ocidental moderna e o processo de desenvolvimento econômico, baseado no consumismo e no desperdício. Deste modo, o lixo ${ }^{1}$ é considerado uma das grandes preocupações da sociedade moderna.

"Hoje a degradação do meio ambiente, na forma de contaminação de águas, do ar e de alimentos, é a principal causa de moléstias que afligem a humanidade e a conseqüente piora da qualidade de vida. Com o desenvolvimento da técnica buscava-se conforto, saúde e alta qualidade de vida, ironicamente, essa luta desenfreada em busca de 'uma vida melhor' foi justamente a causa da maior parte dos problemas - seja de saúde, seja de conforto - que vivemos hoje" (Kupstas et all, 1997: 87).

O ser humano parece desconsiderar o fato de que é parte da natureza e, ao destruí-la, destrói a si próprio. Com base no enfoque de Roberto DaMatta, que analisa a sociedade brasileira como heterogênea, desigual, relacional e inclusiva, será possível perceber qual a visão que o brasileiro tem do espaço público e como se comporta diante deste.

Vigotski, (1988:73), referindo-se à interação do ser humano com o meio, diz-que " $O$ controle da natureza e o controle do comportamento estão mutuamente ligados, assim como a alteração provocada pelo homem sobre a natureza altera a própria natureza do homem".

Todavia, lentamente, a sociedade vem demonstrando sinais de consciência quanto a finitude dos recursos naturais, bem como em relação aos danos irreversíveis causados ao ambiente e, conseqüentemente, aos humanos.

Henrique Leff, em sua obra Saber Ambiental, enfatiza: “A emergência da questão ambiental como problema do desenvolvimento, e da interdisciplinaridade como método para um conhecimento integrado são respostas complementares à crise de racionalidade da modernidade” (Leff, 2001:238).

Por conseguinte, Capra em O ponto de Mutação vai corroborar com Leff, quando fala de uma mudança que já começou, de uma nova cultura que está emergindo - grupos de defesa do meio ambiente, organizações antinucleares, grupos de defesa do consumidor, movimentos de liberação social, para citar alguns.

"Todos esses movimentos subscrevem uma visão holística e ecológica da vida, rejeitando o sistema de valores que domina nossa cultura e é perpetuado por nossas instituições sociais e políticas. A nova cultura

\footnotetext{
${ }^{1}$ Aqui será utilizado preferencialmente o termo lixo para designar quaisquer tipos de resíduos. Vale salientar ainda que a natureza trabalha em ciclos, onde nada se perde e tudo se transforma. Logo, não existe lixo, propriamente.

Holos, Ano 20, dezembro de 2004 
que está emergindo compartilha uma visão de realidade que ainda está sendo discutida e explorada, mas que se consolidará finalmente como um novo paradigma, destinado a eclipsar a visão de mundo cartesiana em nossa sociedade. (...) A nova estrutura será profundamente ecológica, compatível com as concepções de muitas culturas tradicionais (...)” (Capra, 2001: 255).

Nesse contexto surge a Educação Ambiental como perspectiva de gerar novos valores, visando à construção da racionalidade ambiental. Deste modo, este artigo objetiva tecer considerações sobre a percepção e o comportamento do brasileiro do e no espaço público, especificamente em relação ao lixo.

\section{A SOCIEDADE DE CONSUMO}

Com o advento da linha de montagem no início do século XX, pelos americanos Frederick Taylor e Henry Ford, o poder de decisão sobre a produção e o comércio, que antes cabia ao artesão - agora operário -, passa às mãos dos donos das fábricas. Assim, saber e criação não mais eram instrumentos de poder, visto que os donos das fábricas não tinham a necessidade de saber construir o que fabricavam.

As fábricas passam a se organizar em indústrias e estas se organizam em grandes grupos de empresas nacionais e multinacionais. Tais empresas têm o poder de criar necessidades, utilizando-se sobretudo da propaganda - surge a sociedade de consumo.

A sociedade moderna, urbana e industrial, se caracteriza por utilizar bens e serviços em quantidade muito superior à necessária - consumismo. A este respeito, Kupstas et all (1997:99) afirmam: "Não é a tecnologia que atende às necessidades e sim as necessidades é que são criadas para atender à crescente produção e à elaboração cada vez mais diversificada dos bens de consumo".

“Consumo” é uma palavra com raízes francesas e inglesas e originalmente quer dizer destruir, saquear, subjugar, exaurir. Até meados da década de 1920 era um termo usado para referir-se à tuberculose, a doença mais fatal da época. "A metamorfose do consumo, de vício à virtude, é um dos fenômenos mais importantes (...) do século $X X$ ”. (Rifkin, 1995:19).

No início do século passado as pessoas se contentavam em ganhar o suficiente para atender às suas necessidades básicas, preferindo mais tempo livre para o lazer. No entanto, a crescente substituição de trabalhadores por novas tecnologias despertou nos empresários a necessidade de criar o "consumidor insatisfeito", dando nova importância ao marketing. Assim, "moda" passou a ser o lema da época, onde pessoas comuns eram estimuladas a adotar hábitos dos ricos, pois a maioria dos novos produtos exigia mudanças de hábitos. A grande preocupação das empresas era criar necessidades, de tal modo que o consumo acompanhasse a demanda de oferta (Rifkin, 1995). 


\section{LIXO: O MAL DO MUNDO CIVILIZADO}

Dentre as conseqüências do consumo de bens supérfluos pela sociedade contemporânea, destacam-se o excessivo uso dos recursos naturais, a poluição e a enorme produção de lixo. Por conseguinte, o consumismo está estreitamente relacionado com a questão do lixo. Vale salientar que o conceito de lixo é bastante relativo, pois vai desde a mudança de status que sofre qualquer material descartado ao desperdício.

De um modo geral, as atividades humanas sempre produzem resíduos (lixo urbano e industrial, esgotos etc.) cuja disposição inadequada tem causado problemas de contaminação ambiental. Conforme consta no documento Nossa Própria Agenda (1990: 19), "a combinação de resíduos químicos, dejetos tóxicos, emissões de veículos motorizados e outros poluentes urbanos constituem importantes riscos para a saúde de todos os cidadãos”.

Um dos maiores problemas do lixo é a ausência de estrutura para dispor dele e fazer seu tratamento. O Geo Brasil 2002 (BRASIL, 2002) contém a comprovação de que o destino dado ao lixo urbano produzido no Brasil está assim disposto: 0,1\% é incinerado, 0,9\% é submetido a compostagem, $10 \%$ depositado em aterros sanitários, cerca de $13 \%$ em aterros controlados e a exorbitante quantidade de $76 \%$ é depositado a céu aberto, nos chamados "lixões" - terrenos onde se acumulam enormes montanhas de rejeitos a céu aberto, que, além de degradar a paisagem, produzir mau cheiro e entupir bueiros, aumentando a possibilidade de enchentes, são verdadeiros focos de contaminação, causando vários tipos de problemas ambientais e de saúde pública. Os lixões são atrativos de vetores que em contato com os humanos transmitem vários tipos de doenças que podem até matar.

\section{PRIVADO X PÚBLICO: O COMPORTAMENTO DO BRASILEIRO}

Em seu livro A casa \& a rua, o antropólogo brasileiro Roberto DaMatta faz uma leitura do comportamento do brasileiro. "Casa” e "rua” são para ele fundamentais para compreender a sociedade brasileira de forma globalizada, isto é, uma realidade que forma um sistema com suas próprias leis e normas, que são feitas e refeitas através de um complexo sistema de relações sociais. Assim afirma: "No caso do Brasil temos uma casa complicada" (DaMatta: 1997:14).

Dentro da análise de DaMatta, “casa” e "rua” não designam simplesmente espaços geográficos, mas acima de tudo "entidades morais, esferas de ação social, províncias éticas (...), domínios culturais institucionalizados” (DaMatta: 1997:15). A análise da sociedade brasileira feita sob as "esferas de significação social": casa, rua e outro mundo a religião (igreja), vai demonstrar que as pessoas mudam de opinião dependendo do contexto, das circunstâncias. Enquanto em casa todos são "supercidadãos" - lugar onde se pode fazer até mesmo coisas condenadas na rua -, no espaço público a sociedade relacional tem a todos como "subcidadãos", o que justifica o comportamento extremamente negativo em relação às coisas públicas. Segundo o autor:

“Jogamos o lixo para fora de nossa calçada, portas e janelas; (...) somos até mesmo capazes de depredar a coisa comum, utilizando aquele célebre e não analisado argumento segundo o qual tudo o que fica fora de nossa casa 'é um problema do governo!' Na rua a vergonha da desordem não é mais nossa, mas do Estado. Limpamos 
ritualmente a casa e sujamos a rua sem cerimônia ou pejo...”

(DaMatta: 1997:20)

A análise de DaMatta demonstra que não há coerência no comportamento do brasileiro. Há uma cidadania em casa, outra no centro religioso e outra na rua, sendo esta última a mais negativa. Enfatiza ainda que o discurso que predomina é muito mais o da rua do que o da casa. "O comportamento esperado não é uma conduta única nos três espaços, mas diferenciado de acordo com o ponto de vista de cada uma dessas esferas de significação" (DaMatta, 1997:48). Todavia, embora muitos brasileiros falem a mesma coisa em todos os espaços sociais, a casa, a rua e o outro mundo influenciam diretamente nas mudanças de atitudes.

O autor procura demonstrar em sua abordagem que o Brasil tem uma visão complexa e múltipla de si mesmo como sociedade e define a comunidade no Brasil como heterogênea, desigual, relacional e inclusiva.

\section{A EDUCAÇÃO AMBIENTAL E A FORMAÇÃO DE ATITUDES}

Em 1992, no Rio de Janeiro foi realizada a Conferência das Nações Unidas sobre Meio Ambiente e Desenvolvimento, que aprovou um documento, denominado Agenda 21 (CNUMAD, 1992), onde ficou estabelecido um pacto pela mudança do padrão de desenvolvimento global para o próximo século - o atual. A questão da formação de atitudes em relação ao lixo é tratada em vários capítulos entre os 40 que a compõem.

Notadamente no capítulo 21 - Manejo Ambientalmente Saudável dos Resíduos Sólidos e Questões Relacionadas com os Esgotos - define-se que a estrutura de ação necessária em relação a esta temática, deve apoiar-se em uma hierarquia de objetivos e centrar-se em quatro áreas relacionadas com os resíduos, a saber:

“- Redução ao mínimo dos resíduos;

- Aumento ao máximo da reutilização e reciclagem ambientalmente saudáveis dos resíduos;

- Promoção do depósito e tratamento ambientalmente saudáveis dos resíduos;

- Ampliação do alcance dos serviços que se ocupam dos resíduos.”

(CNUMAD - Cap 21, 1992, p.01)

Com efeito, na Agenda 21 brasileira, elaborada em 2000, visando priorizar as estratégias de ações mais urgentes para a realidade do país, consta um alerta para a situação dos padrões de consumo do brasileiro, que acabam por determinar a quantidade e o tipo de lixo produzido: enquanto estes não se alterarem, aumentará a quantidade de lixo produzido, alcançando-se volumes difíceis de serem coletados. A este respeito, apresentam-se possibilidades para mitigação deste diagnóstico:

"A revisão de tais padrões [de consumo] e o investimento em pesquisa $e$ em experimentação tecnológica também são condições para a sustentabilidade das cidades. A alteração de tais padrões tem sofrido resistência, em todo o mundo, por inércia do próprio sistema produtivo, pelos custos envolvidos na alteração de produtos 
industriais e pela ausência da dimensão ambiental nos orçamentos públicos e na composição de custos de produtos”. BRASIL (2000:44)

Além da necessidade de tratar a questão do lixo numa perspectiva de políticas públicas, Scarlato (2003, p.62), dá outro enfoque: “(...) a problemática do lixo é relativamente simples de ser equacionada, segundo uma solução de compromisso entre custos $x$ benefícios (...) desprezar o 'lixo', é no mínimo, um 'luхо' e uma irresponsabilidade”. Ele se refere às diversas possibilidades de reaproveitamento e reciclagem dos resíduos desprezados pela sociedade, sendo esta inclusive, uma tendência mundial.

Assim, a problemática ambiental, notadamente em relação ao lixo, como um reflexo da modernidade, coloca a necessidade de criar uma consciência a respeito de suas causas e possibilidades de resolução, passando por um processo educativo desde a formulação de imaginários coletivos e reorientação dos valores em relação à natureza, até a elaboração de novas teorias sobre as relações ambientais de produção e reprodução social, e a construção de novas formas de desenvolvimento.

\section{CONCLUSÃO}

Em linhas gerais, a formação de atitudes é uma construção que se dá socialmente, coletivamente. É preciso acentuar que o comportamento do brasileiro com o público, como analisa DaMatta, geralmente se dá de forma negativa. Ainda na abordagem do autor, quando trata especificamente da conduta do brasileiro em relação ao lixo - reflexo das sociedades de consumo contemporâneas -.o que se percebe é que as pessoas normalmente "livram-se" do lixo que produzem; fato este comprovado com os dados estatísticos explicitados no presente artigo.

Isto posto, a Educação Ambiental desponta na perspectiva de gerar novos valores, visando a construção da racionalidade ambiental, objetiva ainda inserir nos processos educativos temas que discutam e promovam a melhoria do ambiente e da qualidade de vida. Todavia, consta nos Parâmetros Curriculares Nacionais - PCNs/Meio Ambiente (Ministério da Educação, 2000) que, embora recomendada por todas as conferências internacionais, exigida pela Constituição e declarada como prioritária por todas as instâncias de poder, a Educação Ambiental está longe de ser uma atividade tranqüilamente aceita e desenvolvida, porque ela implica mudanças profundas. Ao contrário, quando bem realizada leva a mudanças de comportamento pessoal e a atitudes e valores de cidadania que podem ter fortes conseqüências sociais.

Assim, a Educação Ambiental surge como instrumento capaz de provocar na sociedade as mudanças de comportamento requeridas pela realidade ambiental. A reciclagem do lixo, por exemplo, assume um papel fundamental na preservação do meio ambiente. Não obstante, é imprescindível que sejam revistos os padrões atuais de consumo, de modo que desperte nas pessoas uma preocupação em gerar quantidades cada vez menores de lixo, evitando desperdícios e reutilizando, ao máximo possível, embalagens que seriam descartadas. Tal mudança de atitude será fruto de uma Educação Ambiental permanente, com reflexos diretos na qualidade de vida da população. 


\section{REFERÊNCIAS BIBLIOGRÁFICAS}

BRASIL. Ministério do Meio Ambiente; Instituto Brasileiro do Meio Ambiente e dos Recursos Naturais Renováveis. Cidades sustentáveis: subsídios à elaboração da Agenda 21 brasileira. Maria do Carmo de Lima Bezerra e Marlene Allan Fernandes (coord) - Brasília: MMA/IBAMA, 2000. 143p.

Geo Brasil 2002: perspectivas do meio ambiente no Brasil. Brasília: Edições IBAMA, 2002. 447p.

CAPRA, Fritjof. O ponto de mutação. Trad. Álvaro Cabral. São Paulo: Cultrix, 2001. 447p.

COMISSÃO DE DESENVOLVIMENTO E MEIO AMBIENTE DA AMÉRICA LATINA E DO CARIBE. Nossa própria agenda. New York, BID/PNUD, 1990. 240p.

CNUMAD - CONFERÊNCIA DAS NAÇÕES UNIDAS PARA O MEIO AMBIENTE E DESENVOLVIMENTO. Agenda 21 - Rio de Janeiro: Organização das Nações Unidas, 1992.

DAMATTA, Roberto. A casa \& a rua. 5.ed. Rio de Janeiro: Rocco, 1997. 163p.

KUPSTAS, Marcia (org.) Ecologia em debate. São Paulo: Moderna, 1997. 128p. (Coleção debate na escola)

LEFF, Henrique. Saber ambiental: sustentabilidade, racionalidade, complexidade, poder. Trad. Lúcia Mathilde Endlich Orth. Prtrópoles,RJ: Vozes, 2001. 343p.

Ministério da Educação/Secretaria de Educação Fundamental. Parâmetros Curriculares Nacionais: meio ambiente: saúde. Rio de Janeiro, DP\&A, 2000. 128p.

RIFKIN, Jeremy. O fim dos empregos: o declínio inevitável dos níveis dos empregos e a redução da força global de trabalho. Trad. Ruth Gabriela Bahr. São Paulo: Makron Books, 1995. 348p.

SCARLATO, Francisco Capuano e PONTIN, Joel Arnaldo. Do nicho ao lixo: ambiente, sociedade e educação. (Série meio ambiente). 16.ed. São Paulo: 2003. 117p.

VIGOTSKI, Lev Semenovich. A formação social da mente: o desenvolvimento dos processos psicológicos superiores. 6.ed. São Paulo: Martins Fontes, 1998. 191p. 